\title{
Primary excision of cutaneous melanoma: does the location of excision matter?
}

Peter Murchie, Erika Sinclair and Amanda J Lee

\author{
ABSTRACT \\ Melanoma is diagnosed more quickly if primarily \\ excised in primary care, but current guidelines \\ discourage this. The reports of all melanomas excised \\ in north-east Scotland between 1991 and 2007 were \\ analysed for adequacy of excision. Reports were \\ analysed blinded as to source. Of primary biopsies \\ performed in primary care, $72.5 \%$ were reported as \\ completely excised, compared with $69.7 \%$ of those \\ performed in secondary care $(P<0.612)$. The difference \\ remained non-significant following adjustment for \\ important confounders.

\section{Keywords} \\ cancer; melanoma; primary health care; skin \\ neoplasms; surgical procedures, minor.
}

P Murchie, BSc (Med Sci), MBChB, MSc, PhD, senior lecturer in primary care; $A J \mathbf{L e e}, B S c, M S c, P h D$, professor of medical statistics, Centre of Academic Primary Care, University of Aberdeen, Aberdeen. E Sinclair, MBChB, career start general practitioner NHS Grampian, Aberdeen.

Address for correspondence

Peter Murchie, Centre of Academic Primary Care, University of Aberdeen, Foresterhill Health Centre, Westburn Road, Aberdeen, AB25 2AY. E-mail: p.murchie@abdn.ac.uk

Submitted: 25 May 2010; Editor's response: 27 May 2010; final acceptance: 13 July 2010.

(c)British Journal of General Practice 2011; 61: 131-134.

DOI: 10.3399/bjgp11X556272

\section{INTRODUCTION}

The incidence of melanoma in the UK has quadrupled since 1970. ${ }^{1}$ By 2025 an estimated 15500 cases of melanoma will be diagnosed annually. ${ }^{1}$ Melanoma is curable if diagnosed and excised early. ${ }^{1}$ Existing guidelines discourage primary care excision of suspected melanoma, ${ }^{2}$ but evidence is contradictory. ${ }^{3-7}$ Furthermore, two studies demonstrate that melanoma is diagnosed more quickly following primary care excision. ${ }^{7,8}$ Consequently, definitively elucidating the relative quality of primary versus secondary care excision is very important, since current melanoma guidelines may not support the optimal diagnostic pathway. This is explored in this report, in melanomas diagnosed in north-east Scotland between 1991 and 2007.

\section{METHOD}

\section{Setting, subjects, and data collection}

All melanoma pathology reports, issued from Aberdeen Royal Infirmary between January 1991 and July 2007, were scrutinised by a single observer, blinded to the location of excision and clinician submitting the specimen. They were assessed for: type of biopsy, quality of clinical information provided, accuracy of diagnosis, anatomical site of biopsy, prognostic features, and completeness of excision.

\section{Statistical analysis}

Analyses were conducted using SPSS (version 17.0.0). Only primary excisions of melanoma were included. For patients with more than one primary excision, only the first was included. For differences between groups, categorical data were analysed using the $\chi^{2}$ test, patient age with the independent $t$ test, and Breslow thickness with the Mann-Whitney $U$ test. Multivariate analysis of the primary outcome measure (completeness of excision) was conducted using binary logistic regression to explore the independent effect of five potential confounders (patient age and sex, lesion site, specialty of operator, and abstract diagnosis). 


\section{How this fits in}

Diagnosis of melanoma is achieved more quickly when the initial biopsy is performed in primary care. Despite this, current guidelines do not identify a role for GPs in the histological diagnosis of suspicious skin lesions. The evidence underpinning this view comes, in the main, from secondary-care studies, employing short time frames. These data suggest current guidelines should be reconsidered and a large UK prospective study of melanoma excision should be considered.

\section{RESULTS}

Between January 1991 and July 2007, 1790 samples were reported as melanoma at Aberdeen Royal Infirmary: 1263 (72.2\%) reporting primary melanoma and $527(29.4 \%)$ recurrent or metastatic

Table 1. Specialty of operator, anatomical site of biopsy, and biopsy method by setting, $n(\%)$.

\begin{tabular}{|c|c|c|c|}
\hline & Primary care & Secondary care & $P$-value \\
\hline Specialty & & & $<0.001$ \\
\hline$n$ & 262 & 1001 & \\
\hline GP & $157(59.9)$ & $6(0.6)$ & \\
\hline GP frequent exciser ${ }^{a}$ & $93(35.5)$ & $22(2.2)$ & \\
\hline Plastic surgeon & $10(3.8)$ & $512(51.1)$ & \\
\hline Dermatologist & $0(-)$ & $152(15.2)$ & \\
\hline General surgeon & $2(0.8)$ & $218(21.8)$ & \\
\hline Other hospital specialists & $0(-)$ & $91(9.1)$ & \\
\hline Anatomical site & & & $<0.001$ \\
\hline$n$ & 248 & 960 & \\
\hline Head and neck & 32 (12.9) & $260(27.1)$ & \\
\hline Body & $72(29.0)$ & $225(23.4)$ & \\
\hline Upper limb & $61(24.6)$ & $133(13.9)$ & \\
\hline Groins & $0(-)$ & $23(2.4)$ & \\
\hline Lower limbs & $83(33.5)$ & $319(33.2)$ & \\
\hline Site unknown & 14 & 41 & \\
\hline Biopsy method & & & 0.02 \\
\hline$n$ & 262 & 1001 & \\
\hline Excisional & $245(93.5)$ & $895(89.4)$ & \\
\hline Incisional & $2(0.8)$ & $41(4.1)$ & \\
\hline Punch biopsy & $7(2.7)$ & $45(4.5)$ & \\
\hline Total otherb & $8(3.1)$ & $20(2.0)$ & \\
\hline \multicolumn{4}{|l|}{ Information from abstracts } \\
\hline$n$ & 169 & 468 & \\
\hline Abstract diagnosis & & & $<0.001$ \\
\hline Correct & 33 (19.5) & $256(54.7)$ & \\
\hline Incorrect & $30(17.8)$ & $54(11.5)$ & \\
\hline Not stated & $106(62.7)$ & $157(33.5)$ & \\
\hline Abstract quality ${ }^{c}$ & & & 0.032 \\
\hline Comprehensive & $29(17.2)$ & $50(10.7)$ & \\
\hline Adequate & $130(76.9)$ & $401(85.7)$ & \\
\hline Inadequate & $10(5.9)$ & $17(3.6)$ & \\
\hline Biopsy site & & & 0.215 \\
\hline Stated & $160(94.7)$ & $453(96.8)$ & \\
\hline Not stated & $9(5.3)$ & $15(3.2)$ & \\
\hline
\end{tabular}

aGPs who had excised $\geq 5$ melanomas in study period. ${ }^{b} \mathrm{C}$ mprises curettage, shave, operative, enucleation, and amputation. 'Data available only from 29 March 2000 to 5 July 2007. melanoma, of which only five (1.0\%) came from primary care. Between 1991 and 2007 the Information Services Division (ISD) Scotland registered 1156 incident cases ( $91.7 \%$ of the total) from Grampian region, suggesting that the study dataset is complete. ${ }^{\circ}$

Of 1263 primary melanomas, $262(20.7 \%)$ came from primary care and 1001 (79.3\%) from secondary care. For 94 patients having more than one primary melanoma excised, only the first was included. Of 262 primary care biopsies, 103 (39.3\%) were from men, compared with $417(41.7 \%)$ of 1001 from secondary care $(P=0.492)$. The mean (standard deviation $[S D]$ ) age of patients from primary care was 51.8 (17.1) years, compared with 59.4 years (18.3 years) in secondary care $(P<0.001)$.

Data on operator specialty, anatomical site, biopsy method, and quality of information provision are presented in Table 1.

There were no significant differences between biopsies submitted from primary and secondary care in proportions with or without adverse prognostic features (ulceration, lymphatic/vascular invasion, perineural invasion, and previous intradermal naevus). The Clark level was lower in primary care biopsies $(P=0.016)$. In primary care biopsies the median (interquartile range [IQR]) Breslow thickness was $0.9 \mathrm{~mm}(0.4-1.85 \mathrm{~mm})$ compared with $1.0 \mathrm{~mm}(0.4-2.3 \mathrm{~mm})$ for secondary care $(P=0.073)$.

Table 2 compares the completeness of excision of samples received from primary and secondary care. Table 3 shows the results of multiple logistic regression to examine if setting (primary/secondary care) was an independent predictor of excision completeness after adjusting for potential confounders. Following multiple adjustment, the adjusted odds ratio for complete excision in primary care was $1.16(95 \%$ confidence interval $[\mathrm{Cl}]=0.34$ to $3.97, P=0.819$ ).

\section{DISCUSSION}

\section{Summary of main findings}

About $20 \%$ of melanomas were excised in primary care, according with previous UK reports, but much lower than in Australia. ${ }^{3-8,10}$ There was no significant difference in Breslow thickness of biopsies excised in either setting, as has been seen before. ${ }^{4,5,7}$ As previously reported, GPs in this study were less likely to state the correct diagnosis, which has been interpreted as demonstrating that GPs have poorer diagnostic skills. ${ }^{3-5}$ Alternatively, GPs could be excising atypical melanomas that are harder to diagnose, as suggested by a systematic review finding no difference between the diagnostic skills of dermatologists and primary care physicians. ${ }^{1}$ 
Furthermore, if GPs excise melanomas with similar quality to secondary care colleagues, differences in diagnostic skill do not matter.

\section{Strengths and limitations of the study}

The researcher was blinded to the source of the biopsy, thus removing observational bias, which is a major issue in previous studies. Data were gathered by a single observer to limit variability in subjective analysis, although a second researcher with a similar background should perhaps have analysed a sample of reports to ensure inter-rater reliability. The study also limited bias by excluding secondary excisions (that is, wide local excisions).

This was a retrospective observational study and not a randomised comparison. GPs may remove more straightforward lesions creating bias in their favour; however, no differences exist even after adjustment for biopsy site. In contrast, GPs could be referring obviously malignant lesions and removing those with an atypical appearance, accounting for differences in diagnostic accuracy. Therefore, it is likely that lesions in primary care are still being properly excised even if melanoma is not suspected. The data presented are from Grampian region only, so it is not clear if these results apply more widely. Most importantly, there are no data on long-term outcomes and it is not known which patients went on to die or develop recurrences. A further point to note is the wide confidence intervals around the odds ratio for excision completeness, which probably emphasises the relative rarity of melanoma and the size of study that is required to provide definitive answers on excision location.

\section{Comparison with existing literature}

Previous studies comparing primary and secondary care excision of melanoma are contradictory. ${ }^{4-7}$ Three have reported greater likelihood of incomplete melanoma excision in primary care. ${ }^{4-6}$ One, however, was based on only 126 biopsies, and another divided data into 'complete and adequate excision' and 'complete and inadequate excision', without explaining the difference. ${ }^{4,5}$ This is important, since the statistical difference disappears when the data are analysed without this non-defined distinction. ${ }^{5}$ However, a more recent study, originating in primary care, reported similar results to those of the present study, finding no significant difference in completeness of excision between primary and secondary care doctors. ${ }^{7}$ It is noteworthy that, of previous studies, only those conducted by secondary care doctors have found evidence of poorer-quality GP excision, and in none of these
Table 2. Outcome of biopsy by setting, $\boldsymbol{n}(\%)$.

\begin{tabular}{lccr} 
& $\begin{array}{c}\text { Primary care, } \\
n=262\end{array}$ & $\begin{array}{c}\text { Secondary care, } \\
n=1001\end{array}$ & P-value \\
\hline Completeness of excision & & & 0.612 \\
Completely excised & $190(72.5)$ & $698(69.7)$ & \\
Incompletely excised & $52(19.8)$ & $227(22.7)$ & \\
Not stated & $20(7.6)$ & $76(7.6)$ & 0.034 \\
\hline Second pathology opinion & & & \\
$\quad$ Referred & $29(11.1)$ & $71(7.1)$ & \\
Not referred & $233(88.9)$ & $929(92.9)$ & \\
\hline
\end{tabular}

\section{Table 3. Multiple logistic regression model of location of excision predicting completeness of excision.}

\begin{tabular}{lcr} 
& Adjusted $\mathrm{OR}^{\mathrm{a}}(95 \% \mathrm{Cl})$ & P-value \\
\hline $\begin{array}{l}\text { Primary care excision } \\
\text { (base }=\text { secondary care excision) }\end{array}$ & $1.16(0.34$ to 3.97$)$ & 0.819 \\
\hline Male sex (base $=$ female) & $1.00(0.64$ to 1.56$)$ & 0.994 \\
\hline Age $(+1$ year) & $1.02(1.01$ to 1.03$)$ & 0.001 \\
\hline Speciality (base $=$ GP) & & \\
GP frequent exciser & $1.06(0.48$ to 2.32$)$ & 0.884 \\
Plastic surgeon & $0.34(0.09$ to 1.28$)$ & 0.110 \\
Dermatologist & $1.31(0.32$ to 5.34$)$ & 0.706 \\
General surgeon & $1.07(0.27$ to 4.33$)$ & 0.923 \\
Other hospital specialist & $0.98(0.19$ to 4.9$)$ & 0.976 \\
\hline Correct abstract diagnosis & $1.06(0.82$ to 1.36$)$ & 0.634 \\
(base $=$ incorrect) & & \\
\hline Site (base $=$ head and neck) & & \\
Body & $0.39(0.21$ to 0.70$)$ & 0.002 \\
Upper limb & $0.33(0.16$ to 0.67$)$ & 0.002 \\
Lower limb & $1.98(0.36$ to 8.43$)$ & 0.358 \\
Other & $0.69(0.39$ to 1.20$)$ & 0.189 \\
\hline
\end{tabular}

$\mathrm{OR}=$ odds ratio. ${ }^{a}$ Adjusted for the potential confounders of sex and age of the patient; the speciality of the doctor submitting the specimen to the pathology laboratory (GP, GP frequent exciser, plastic surgeon, dermatologist, general surgeon, other secondary care specialist); the accuracy of any stated diagnosis; and the biopsy site (head and neck, body, upper limb, lower limb, groin and perineum).

studies do the investigators appear to have been blinded to the site of origin of the report. ${ }^{3-5}$

\section{Implications for clinical practice and future research}

This study found no evidence to support the belief that melanomas are more likely to be excised inadequately in primary care. In the context of UK policy drives to reduce cancer diagnostic delays, and given that GP excision of melanoma results in more rapid diagnosis, guidelines should be reexamined. ${ }^{7,8,12}$ Currently, however, the relative outcomes of patients receiving their primary biopsy in primary or secondary care are unknown, although existing evidence suggests that survival is not compromised by having a melanoma excised in primary care. ${ }^{6}$ This, along with a large-scale national prospective study, is a key issue for future researchers to consider. 


\section{Funding body}

The study was not funded by an external grant award. The University of Aberdeen acted as sponsor for the study. Peter Murchie is jointly funded by the Scottish School of Primary Care and the University of Aberdeen. Erika Sinclair is employed by NHS Grampian and Amanda $\mathrm{J}$ Lee is employed by the University of Aberdeen.

\section{Ethical approval}

This was a clinical audit of anonymised data. Ethical approval was not required.

\section{Competing interests}

The authors have stated that there are none.

\section{Acknowledgements}

We wish to acknowledge, Dr William D Thompson, consultant pathologist NHS Grampian, retired, and $\mathrm{Mr}$ Graham McHardy, data manager in the Department of Pathology, University of Aberdeen, for assisting the construction of the study database.

\section{Discuss this article}

Contribute and read comments about this article on the Discussion Forum: http://www.rcgp.org.uk/bjgp-discuss

\section{REFERENCES}

1. Cancer Research UK. CancerStats Key Facts skin cancer statistics key facts. http://info.cancerresearchuk.org/cancerstats/types/skin/ (accessed 5 Jan 2011).

2. National Institute for Health and Clinical Excellence. Guidance for Cancer Services. Improving outcomes for people with skin tumours including melanoma: the manual. The London: National Institute for Health and Clinical Excellence, 2006.

http://www.nice.org.uk/nicemedia/live/10901/28906/28906.pdf (accessed 5 Jan 2011).

3. McWilliam LJ, Knox F, Wilkinson N, Oogarah P. Performance of skin biopsies by general practitioners. BMJ 1991; 303(6811): 1177-1179.

4. Herd RM, Hunter JAA, McLaren KM, et al. Excision biopsy of malignant melanoma by general practitioners in south east Scotland 1982-91. BMJ 1992; 305(6867): 1476-1478.

5. Khorshid SM, Pinney E, Newton Bishop JA. Melanoma excision by general practitioners in North-East Thames region, England. Br J Dermatol 1998; 138(3): 412-417.

6. McKenna DB, Marioni IC, Lee RJ, et al. A comparison of dermatologists, surgeons and general practitioners surgical management of cutaneous melanoma. Br J Dermatol 2004; 151(3): 636-644.

7. Neal RD, Cannings-John R, Hood K, et al. Excision of malignan melanoma in North Wales: effect of location and surgeon on time to diagnosis and quality of excision. Fam Pract 2008; 25(4): 221-227.

8. Murchie P. Treatment delay in cutaneous melanoma: from diagnosis to definitive treatment. Qual Prim Care 2007; 15(6): 345-351.

9. Dickinson HO, Salottie JA, Birch PJ, et al. How complete and accurate are cancer registrations notified by the National Health Service Central Register for England and Wales? J Epidemiol Community Health 2001; 55(6): 414-422.

10. Askew DA, Wilkinson D, Shluter PJ, Eckert K. Skin cancer surgery in Australia 2001-2005: the changing role of the general practitioner. Med J Aust 2007; 187(4): 210-214.

11. Suephy C, Chen, Dena M, et al. A comparison of dermatologists' and primary care physicians' accuracy in diagnosing melanoma. Arch Dermatol 2001; 137(12): 1627-1634.

12. Richards MA. The National Awareness and Early Diagnosis Initiative in England: assembling the evidence. Br J Cancer 2009; 101 Suppl 2: S1-S4. 